\title{
Research on Temporal-spatial Distribution of Islamic Cultural Heritage in China: Based on Cultural Relics Protection Units
}

\author{
Chen Dong-jun ${ }^{1, a}$, Xie Hong-bin ${ }^{2, b,{ }^{*}}$ \\ 1,2School of Geography Sciences, Fujian Normal University, Fuzhou, Fujian Province, China \\ adongjun925@163.com, bxiehongbin933@sina.com
}

Keywords: Islam, Cultural heritage, Temporal-spatial distribution, Cultural relics protection unit, China.

\begin{abstract}
The Islamic cultural heritage of China, as the historical mark of the spread of Islam in China, not only holds historical-cultural, scientific, and artistic value but also serves modern functions such as patriotic education and tourism. This research on the temporal-spatial distribution of the Islamic cultural heritage enrolled in cultural relics protection units in China found that Islamic cultural heritage in China can be characterised as being of 'large distribution and high concentration' in space, and most of them date back to the Ming-and-Qing era. The evolution of the Islamic cultural heritage in China can be divided into four historical stages: it was first distributed along the southern coast in the Tang-and-Song era, next expanded to most areas of China except for the southwest and northeast in the Yuan era, then spread to the whole of China in the Ming-and-Qing era, and finally slightly developed as a whole, and concentrically distributed in the northwest and northeast in modern times. The distribution of these heritage sites depended on three historical-cultural factors: the propagation conditions of Islam, the policy and attitude of governors, and awareness of Islam missionary work and Islamic nationality.
\end{abstract}

\section{Introduction}

Research on cultural heritage began more than 40 years ago, since it was explicitly proposed by the United Nations Educational Scientific and Cultural Organization (UNESCO) in 1972, with the aim of focusing on its protection [1], exploitation and utilisation [2], value assessment [3-4], implementation of law and regulation [5], tourism development [6-7], analysis of community involvement [8-9], archives management [10], property rights [11], spatial distribution and factors influencing this distribution [12-13], and so on. Most studies were conducted from the perspectives of history, archaeology, and architecture. Cultural heritage, as a witness of social-cultural changes in a region, is considered as the carrier of ancient cultural information through either tangible remains or relics or through the folklore. However, limited research has been conducted on its temporal-spatial distribution characteristics, and the factors influencing such distributions from the view of historical geography.

Islamic culture in China has a long history, and its heritage is represented in things that express the value of Islamic history, art, and science, and things that are closely related to a Muslim's life, or are an embodiment of traditional culture. These include tangible heritage, such as mazars, mosques (or masjid) and stone inscriptions, as well as intangible heritage, such as festivals, religious restrictions, doctrines, institutions, factions, and art. Islamic cultural heritage comprises vivid teaching materials and valuable wealth of artefacts and information that help contemporary Muslim youth to understand, perceive, inherit, and develop the Islamic culture [14]. The existing research on Islamic cultural heritage in China has largely focused on its protection and development [15], its values [16], characteristics [17] and its relationship with cultural identity [18], with only limited research offering little information or insight regarding its temporal-spatial distribution and the factors influencing such distribution.

According to the Act of the Preservation of Cultural Relics Promulgated by People's Republic of China, the cultural relics protection unit (CRPU) is the umbrella name for immovable cultural relics 
that are protected by law, including relics with historic, artistic, and scientific value, and typical material objects that reflect the social system, social production or the lives of various nationalities in different historical periods ${ }^{1}$. Many Islamic cultural heritage relics appear in the CRPU List of China and some are even considered as state-level, which indicates their outstanding value and representativeness [19]. Therefore, it is of great practical importance to examine China's Islamic cultural heritage based on the relics present in the CRPU. The relics of Islamic cultural heritage recognized in CRPU are the witnesses of the inheritance of Islamic historical culture in China and the carriers of historical information. Accordingly, this research studied the Islamic cultural heritage relics using the data of the CRPU List of China, analysed their temporal-spatial distribution and the spread and development of Islam in China, and then probed the factors influencing this distribution. This research not only provides the practical basis for learning the development of Islam in China, the formulation of the ethnic and religious policies, and protection and development of cultural heritage but also offers the theoretical reference for research on geographical distribution, spread, development, and cultural evolution of a religion.

\section{Materials and methods}

\subsection{Materials}

According to The Lists of Islamic CRPU in China published on China Islamic Association's website in $2015^{2}$, there are 40 state-level, 103 provincial-level and 223 municipal-level Islamic CRPU in China. The information of their locations and time contained in this list were data sources were used to analyse the temporal-spatial distribution. The location information, which is detailed and simple mixed, was all uniformly narrowed down to city-level. As for the time of information, the era to record the start and the end time were used. Additionally, after consulting the research by Wen-qi Yang about Islamic CRPU [16], 16 state-level Islamic CRPUs were added to the final data. The data were then sorted into four types: mosque, tomb, stone inscription, and others, among which the mosques constituted $90.6 \%$ of the data sample (see Table 1).

Table.1. Stastics of Islamic of China

\begin{tabular}{cccc}
\hline Types & State-level & Provincial-level & Municipal-level \\
\hline Mosque & 34 & 98 & 214 \\
\hline Tomb & 15 & 4 & 3 \\
\hline $\begin{array}{c}\text { Stone } \\
\text { Inscription }\end{array}$ & 1 & 0 & 4 \\
\hline Others & 6 & 1 & 2 \\
\hline
\end{tabular}

\subsection{Methods}

At first, the database of Islamic cultural heritage was set up based on the location and time information extracted from The Lists of Islamic CRPU in China. Thereafter, its temporal-spatial distribution was analysed using the number-shape combination method and visualised by ArcGIS 10 . Then, the characteristic of distribution, centralised or decentralised in space or time, was further investigated. In addition, in factor analysis, relevant index was used to prove the relationship between the number of Muslims and the mosques in a region.

\subsubsection{Lorenz curve and Gini coefficient}

Lorenz curve is a graphical method commonly used to describe the degree of inequality in social income distribution, and Gini coefficient is the indicator to analyse the difference of income distribution of residents and evaluate the fairness of such differences. If the Gini coefficient is less than 0.2 , it indicates an 'absolutely fair' distribution, while a coefficient more than 0.5 indicates

\footnotetext{
${ }^{1}$ The People's Republic of Cultural Relics section two, chapter one. http://www.scio.gov.cn/xwfbh/xwbfbh/wqfbh/2015/33065/xgbd33074/Document/1440173/1440173.htm.

2 The download link of The Lists of Islamic CRPU in China is

http://www.chinaislam.net.cn/cms/download/201503/03-8000.html.
} 
'greatly unfair' distribution. In geography, Lorenz curve and Gini coefficient are mostly used to measure the spatial distribution of some geographic elements and to objectively and directly reflect the spatial variability [20]. In this study, the temporal-spatial distribution of Islamic cultural heritage relics was analysed by Gini coefficient and further tested by Lorenz curve. The formula of Gini coefficient is as follows:

$$
G=1-\frac{1}{n}\left(2 \sum_{i=1}^{n-1} W_{i}+1\right)
$$

In the formula, ${ }^{W_{i}}$ is the proportion of the quantity of Islamic cultural heritage relics in province $\mathrm{i}$ out of the total number of relics in the country; $n$ is the number of provinces; the value of $G$ is $0-1$, and a greater value of $G$ indicates more concentrated distribution.

\subsubsection{Kernel density analysis}

Kernel density estimation is used to estimate the unknown density in probability theory, and it can be used in spatial analysis by Kernel density mode of ArcGIS 10. It is based on input elements of point or line to calculate per-unit area value in a given search radius, and these elements are then fit into a smooth cone-shaped surface. In this study, Kernel density was used to analyse the spatial concentration and decentralisation of Islamic cultural heritage relics in each era.

2.2.3 Pearson correlation coefficient

Pearson correlation coefficient is an index to measure the linear relationship between two variables, which can be realized by the correlation analysis function of SPSS. Here it was used to measure the correlation between distribution of Muslims and mosques in each province. The formula for Pearson correlation coefficient is as follows:

$$
r=\frac{N \sum X_{j} Y_{j}-\sum X_{i} \sum Y_{j}}{\sqrt{N \sum X_{j}^{2}-\left(\sum X_{j}\right)^{2}} \sqrt{N \sum Y_{j}^{2}-\left(\sum Y_{j}\right)^{2}}}
$$

In the formula, $N$ is the number of provinces; ${ }^{X_{j}}$ and ${ }^{Y_{j}}$ represent the number of Muslims and mosques, respectively, in province ${ }^{i}$. The value of $r$ is $-1-1$, and the greater $r$ is, the stronger the correlation is.

\section{Results}

\subsection{Temporal-spatial distribution characteristics of Islamic cultural heritage among CRPU}

\subsubsection{Characteristics of temporal distribution}

The relics of Islamic cultural heritage among CRPU span over Tang, Song, Yuan, Ming, Qing and modern times in China, and the quantity of relics in each era is shown in Fig. 1. The quantity was less in Tang, Song, and Yuan Dynasties, but sharply increased in Ming and reached the maximum in Qing, and dramatically reduced in modern times. Moreover, the relics of Islamic cultural heritage from Ming and Qing Dynasties constituted $83.5 \%$ of the total number of relics.

\subsubsection{Characteristics of spatial distribution}

The Islamic cultural heritage relics in CRPU, as shown in Fig. 2, are widely distributed in each province, except for Tibet and Jiangxi, and are mostly located in Xinjiang and Shandong provinces, followed by surrounding provinces, such as Qinghai, Hebei, and Henan, with quantities gradually decreasing from Xinjiang and Shandong provinces to the middle of China. Calculated according to the quantity of Islamic cultural heritage relics in each province, the Gini coefficient of spatial distribution was 0.51 , which indicated that the relics were highly concentrated in space. After further verification by using the Lorenz curve, the quantity of Islamic cultural heritage relics in Xinjiang, Shandong, Qinghai, Hebei, Henan, Beijing, Yunnan, Anhui, Liaoning, and Ningxia provinces constituted more than $70 \%$ of the total number of relics. Moreover, five provinces of Xinjiang, Shandong, Qinghai, Hebei, and Henan contained $48 \%$ of all relics, showing that the relics were significantly and highly concentrated in spatial distribution. 

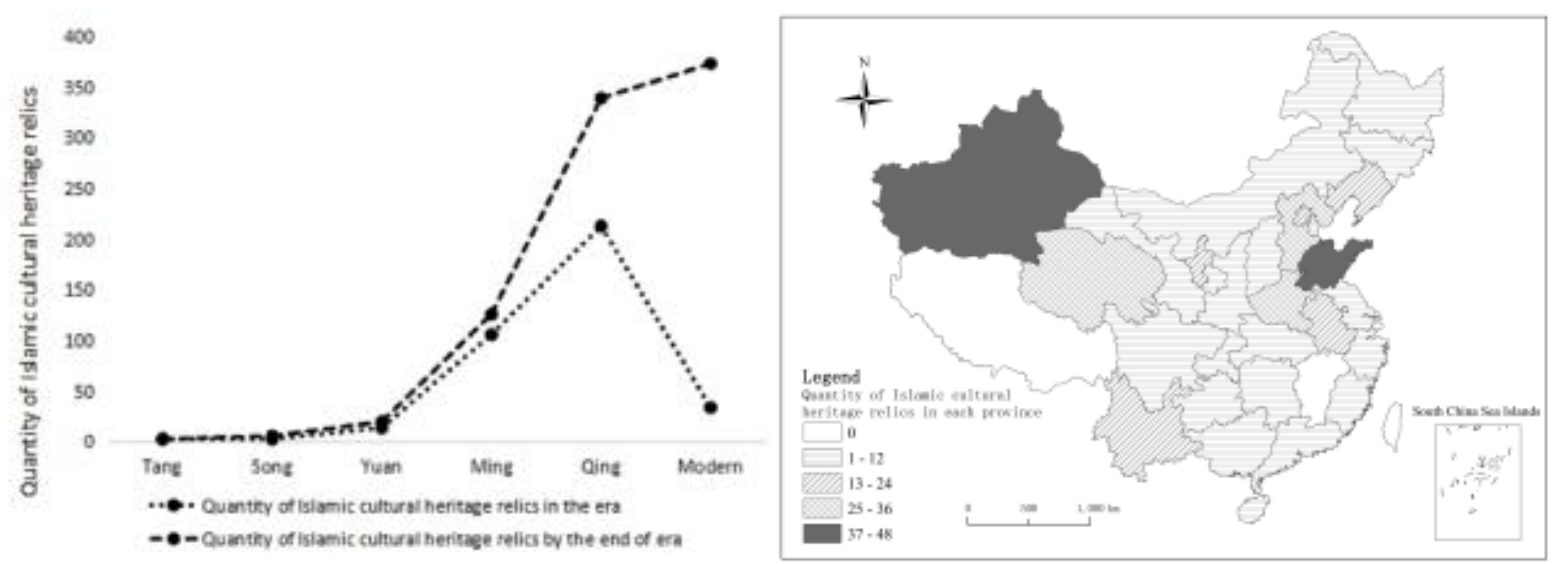

Fig. 1. Statistics of relics of Islamic cultural heritage indifferent eras Fig. 2. Distribution of Islamic cultural heritage relics

\subsection{Temporal-spatial distribution characteristics of Islamic cultural heritage in different eras}

The increase in followers of a religion reflects its development and spread in a certain region [21]. The mosque, around which Muslims usually live, is the most important place for Muslims' religious activities and cultural lives, and its quantity is largely consistent with the population of Muslims in the region [22]. Correlation analysis between the number of mosques and Muslims in each province of China generated the Pearson correlation coefficient of $0.94^{1}$, showing a highly positive correlation. Among the Islamic cultural heritage relics in CRPU, mosques constituted the highest percentage, accounting for $90.6 \%$ of all relics. The distribution of Islamic cultural heritage relics is closely related to and even can be regarded as the spread and development of Islam.

The temporal-spatial distribution of Islamic cultural heritage can be divided into 4 stages: Tang-and-Song era, Yuan era, Ming-and-Qing era, and modern times (Fig. 3). The Islamic cultural heritage relics of the Tang-and-Song era are few and are all distributed along the southern coast. The relics of the Yuan era are well developed compared with the Tang-and-Song era, both in terms of substantial growth in number and considerable expansion in space, extending to most areas of China except for the southwest and the northeast, evidencing the characteristic of 'large distribution and small concentration' of Islamic cultural heritage in China as a whole. The relics of the Ming-and-Qing era expanded all over China. They are highly concentrated in certain areas, which established the distribution pattern as seen today. The relics of modern times mainly developed in the northwest (Xinjiang, Gansu, Ningxia and Qinghai provinces) and the northeast.

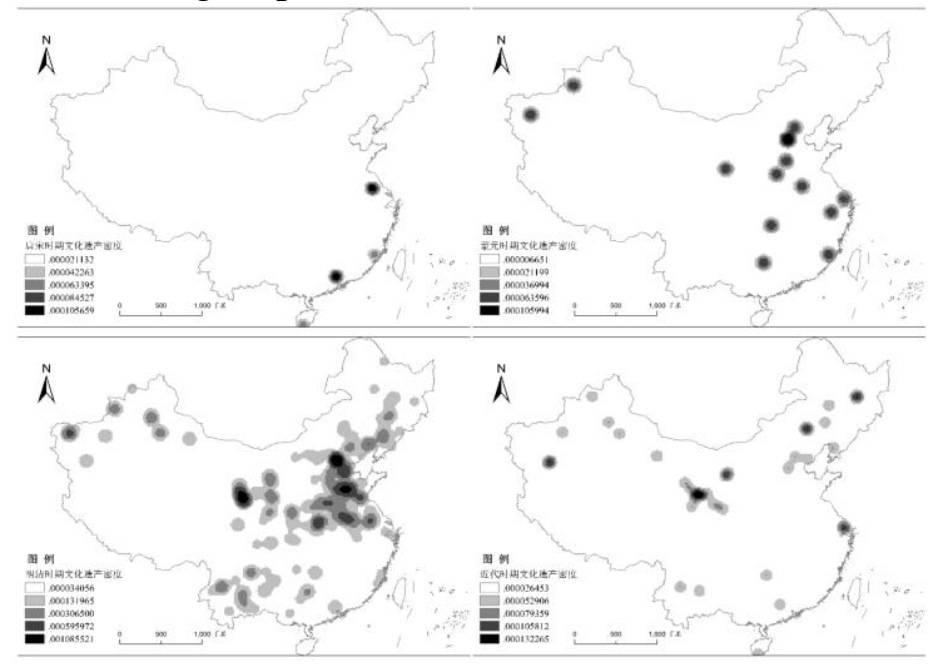

Fig. 3. Temporal-spatial distribution of Islamic cultural heritage relics

\footnotetext{
${ }^{1}$ The Pearson correlation coefficient between the quantity of mosques and Muslims in each province was 0.998 in 2004 , and 0.945 in 2015. The data was obtained from China Islamic Association website

(http://www.chinaislam.net.cn/cms/whyj/yslgk/201205/21-58.html) and China National-religion website

(http://www.mzb.com.cn/html/report/150333944-1.htm).
} 


\section{Discussion}

\subsection{Distribution of Islamic cultural heritage and the development of Islam in China}

\subsubsection{Tang-and-Song era}

The economic and cultural exchanges between the Arab region and China were established across Overland and Maritime Silk Road in the Qing-and-Han era and continued to the Tang Dynasty. The open socioeconomic environment and cultural atmosphere at that time promoted frequent communication. According to the records of Prime Tortoise of the Record Bureau political contacts between the two sides of Tang and Taziks empire amounted to 39 times from the second year of Tang Yonghui (AD 651) to the fourteenth year of Zhenyuan (AD 798). The purpose of presenting tributes to the Tang Dynasty by Muslims was to gain business benefits rather than to advance missionary work; as a result, the transmission of Islam was limited to specific people within the regions only, for example to the Taziks mission alone, and did not affect any Chinese businesses. Additional limitation to the spread of Islam at this time included the lack of a comprehensive doctrinal system of Islam, the presence of different languages, and barriers in inter-cultural communication.

After the middle era of Tang, numerous intrusions from Turkey and Tibet frequently blocked Overland Silk Road, and the regime opposition among Liao, Xia, and Jin almost paralysed the Overland Silk Road during the Song Dynasty. Thus, by the Tang-and-Song era, the Maritime Silk Road became the main way for spreading Islam to China. Compared to the Overland Silk Road, the Maritime Silk Road was not only beneficial for continuous navigation, but also had economic, political, and time-lengthening advantages for spreading Islam. China's economic gravity started to move to the south since the Rebellion of An Lushan and Shi Siming, and the movement ended in the Southern Song Dynasty with the saying 'Su \& Hang cooked, the world is adequate'. Thus, the southern coastal cities with advanced economies became the main area where Islam spread. With the maritime trade booming gradually, the governors paid more attention to taxes and successively set Shibosi in Guangzhou, Hangzhou, Ningbo, and Quanzhou - that is to say, the Maritime Silk Road received political guarantee with the governors' support. The monsoon seasons lengthened the time of round trips between China and Arabia to two years, thus delaying Muslims' return to Arabia, and creating an opportunity for them to spread Islamic culture in the southern coast. In addition, the southern coast was also the first choice for Islam mission. 'There were 4 sages (among Muhammad's disciples) missioned in China in the Tang Wude era, the one in Guangzhou, another in Yangzhou, and the two others in Quanzhou. Thus, mosques from the Tang-and-Song era are widely distributed in those cities.

The Islamic cultural heritage relics of the Tang-and-Song era are closely related to the path of the spread of Islam in China. As indicated in the saying, 'Islam was carried to China by Arab merchants' ships and camels'; its distribution has been influenced by the rise and decline of the Overland and Maritime Silk Roads.

\subsubsection{Yuan era}

During the Yuan era, the Mongol Empire governed all Islamic countries and areas in the Western regions, including the routes of land transportation between China and the West. Moreover, in a hurry to make the country wealthy, the Yuan government actively advocated and encouraged overseas trade. As a result, Islam spread to China in two directions, to the east and west. Additionally, when Mongolians conquered and unified China, many Arabs, Persians, and other nationalities in Central Asia who were soldiers and believers of Islam were sent to Northwest and Southwest China, Jiangnan, and the Central Plain to reclaim the land [23]. Muslims started to spread in most parts of China, as reflected in the saying 'the Huis lived everywhere during Yuan Dynasty'.

The Mongol governors of the Yuan Dynasty implemented inclusive and free religious policy and even treated Islam with leniency in order to contain other nationalities and maintain its rule. For instance, the Yuan Dynasty appointed the Hui upper class in government bureaucracy, specially assigning Hui's Imam Agent to manage Islam affairs, meanwhile the Huis enjoyed preferential treatments in tax and corvée. With the tolerant political environment and higher social status, 
Muslims gradually gathered around the political centre, Dadu (present-day Beijing). In addition, the Jiaofang (Muslim settlement) system, a mosque-centred living organisation, gathered Muslims around the mosques and functioned as the basic cell to form the national community of Hui, Salar, Dongxiang, Baoan, and so on. These developments shaped Muslims' living pattern to resemble 'small settlements'.

In a word, the Muslims in Yuan era dispersed all over China in small settlements, and accordingly, the Islamic cultural heritage relics were distributed with the characteristic of large distribution and small concentration.

\subsubsection{Ming-and-Qing era}

During the Ming-and-Qing era, Islam continued to spread to China, but the development patterns between inland and the southern coast were quite different. Islamic villages formed a batch inland, some of which evolved from bureaucratic country estates of Yuan army reclamation and others naturally developed with the multiplication of Islam followers [23]. On the other hand, along the southern coast, Islamic heritage developed slowly because of the ban on maritime trade. The Chinese-featured Islamic culture formed in this period, which resulted from the transformation of the Islam transmission pattern, from being self-restrained and enclosed to one marked with communication and integration with Chinese traditional culture. Even the Ming Dynasty showed some respect for Muslims' faith and the Qing Dynasty kept a certain open mind to 'unify the politic, and to respect the custom' towards Islam. However, in order to maintain their rule, the governors intended to assimilate minorities by imposing measures, such as banning Hu's clothing, language, surnames, marriages between $\mathrm{Hu}$ and Han, maritime trade, and so on [24]. These policies worsened the living conditions of Muslims and deterred the Islam missionary work. The integration between Islamic culture and Chinese traditional culture was further facilitated by the formation of the Hui nationality and of Muslim scholars who were well-versed in both Islam and Confucianism, the change of Muslim production mode from commerce to agriculture, the mosque education's adaption to Chinese traditional education system, the social stratification and bureaucratisation of the village system, the wide use of the Chinese language by Muslims, and the introduction of Sufism [24]. The translation activity by Hu-Dengzhou at the end of the Ming Dynasty can be seen as a sign of cultural integration and the change of the Islam transmission pattern [25].

With the development of mosque education, Chinese translation of Islamic classics, Sufism factions, the immigration of 'Go West' and 'Fill Sichuan', Islam further spread in China [25]. The scale and influence of the Islam mission, which integrated Chinese traditional culture, was unprecedented and caused Islam to disperse all over China, with high concentration in certain areas. As a result, Islamic cultural heritage relics from the Ming and Qing Dynasties are distributed in the entirety of China and highly concentrated in some areas.

\subsubsection{Modern times}

During the late period of the Qing Dynasty, the national conflict and class contradiction in Chinese society were further intensified by the Opium War, and the governors' attitude towards Islam transformed from tolerance to harsh political controls and military intervention, such as in the example of brutal repression of Hui uprising in Yunnan province and the northwest. After the 1911 Revolution, although radical bourgeois revolutionists put forward some democratic slogans, such as 'all nationalities are equal' and 'five-nationality unity to be a republic', real equality of nationalities failed to actualise because of various constraints and class conditions. Furthermore, the governors at that time continued the Qing's policy of 'restricting one minority by another minority' and supported the appointment of the upper class to maintain their ruling state, ensuring limits on Muslims' rights in political and social life. The inland Muslims recognized that, to find their social position, they must adapt their beliefs and thoughts to the changing times and that they should awaken and improve national awareness of their need of equal rights. Thus, they started the new culture movement. The movement to promote Islam included measures, such as setting up new schools, publishing Islamic books and magazines, establishing national or regional Islamic groups, developing academic research on Islam and industrial projects, and sending students to study abroad. However, at the same time, the 
revolutionary task of opposing imperialism and feudalism sparked Muslims' patriotism, and Islamic celebrities associated nationality and religion with the fortune of the country and shifted the focus instead to state survival. Such patriotic movements slowed the development of Islam to some degree.

In this period, Islam spread and developed more quickly in Xinjiang, Gansu, Ningxia, Qinghai provinces and the northeast. Xinjiang was governed by Yang Zengxin, Jin Shuren, Sheng Shicai, Kuomingtang, and the Nanking national governments. In that order, appropriate ethnic policies created advantages for Islam's development except for Jin Shuren's ethnic oppression. The conflicts between Ikhwan (one of Sufis' independent sects) and Menhuans seriously damaged the interests of Muslims in Gansu, Ningxia and Qinghai provinces in the period before the implementation of the Chinese communist party's ethnic policy. However, local governments later implemented the said ethnic policy of respecting faith, equalising political status, supporting economy, and promoting the development of cultures. At the end of the Qing Dynasty, as the ban on moving to the northeast was lifted, people were encouraged to move there and develop this region, which was one of the wealthiest areas of Asia before the September 18th Incident (Japanese troops invaded Northeast China and established Manchukuo in September 18th 1931). Thereafter, Japanese militarism intended to sow dissension through Islam, between the Hui, who believe in Islam, and the Han, who do not, and to further govern tolerantly in the northeast in order to obtain the support of the people, and conquer the whole of China. All this objectively provided a free environment for Islamic development.

The Islamic cultural heritage of modern times is mainly distributed in the northwest (Xinjiang, Gansu, Ningxia, and Qinghai provinces) and northeast areas. Although the Islamic cultural heritage continued to develop during this time, the extent of this period's development cannot hold a candle to the development of the Ming-and-Qing era. The limited degree of development during this time was due in part to the short time span, the social and political turbulence, and the attitude of the governors.

\subsection{Factors influencing the temporal-spatial distribution of Islamic cultural heritage}

The temporal-spatial distribution of Islamic cultural heritage in China reflects the spread and development of conditions of Islam in different periods of China, and the changes in distribution have been mainly influenced by the following factors.

\subsubsection{Propagation condition of Islam}

Humans are the main carriers of culture. A culture without special groups to carry it is lifeless, and its spread is caused by the migration of initial carriers [26]. The Muslim merchants trading in China were the initial carriers of Islamic culture. During the Tang-and-Song era, the Overland Silk Road was frequently blocked, leaving the Maritime Silk Road as the main route for Muslim merchants to trade and introduce Islam in China. As such, the Islamic cultural heritage of that time was primarily distributed along the southern coast. The cultural transmission was divided into two stages of 'know' and 'learn or accept' [26]. In the Tang-and-Song era, the lack of a comprehensive doctrinal system of Islam and communication barriers posed by differences in written and spoken language limited the spread of Islam within Muslim groups, and Islam remained unknown to Han and others nationalities. In the Yuan era, the open Overland and Maritime Silk Roads led to the situation of 'the Huis lived everywhere', and the Islamic cultural heritage started to be seen in most areas of China. However, the bans on maritime trade in the Ming-and-Qing era cut off the spread of Islam from the southern coast, and the development of Islamic cultural heritage began to decline.

\subsubsection{Policy and attitude of governors}

Policy and attitude of governors about Islam is also related to Muslims' social survival environment. Whether the governors supported or opposed Islam, their purpose was the same-to maintain dominance; however, their differing attitudes did lead to different policies. To promote the maritime trade and economic development, the policy of Tang and Song governors offered a tolerant social environment to Islam. The Yuan Dynasty, the first minority regime of China, also took a tolerant attitude and policy of 'temper justice with mercy', treating followers of Islam with mercy and cracking down on opponents with resoluteness to assert its rule. In the Ming Dynasty, however, with the development of centralised absolutism, the governors restricted Muslims' right and assimilated 
them, leading to a deterioration of Muslims' life. In early Qing Dynasty, the basic policy of 'politics equalled but custom diversified' benefited Islam development, while in the middle and latter periods of the Qing Dynasty, brutal suppression of Islamic civil strife and the intensification of ethnic and class conflicts caused by foreign aggression led to frequent Hui uprisings. In modern times, the conflicts between China and foreign aggression became significant, and governors mostly adopted the policy of uniting all nationalities to fight against invasion.

In general, most governors adopted a tolerant policy towards Islam and promoted its development, while those in the mid- and late-period of the Qing Dynasty controlled Islam more strictly. Regardless of the differences among them, diverse attitudes and policies of governors in different eras led to different degrees of development of Islam.

\subsubsection{Awareness of Islam missionary work and Islamic nationality}

The ethnic carrier of religious culture is the basic condition for religion to spread and develop in a foreign region [23]. Islam was formed during the mid-Tang Dynasty and then introduced into China. Initially, Muslims came to China with the main purpose of trading rather than doing missionary work, and the Islamic nationality was not yet formed in the Tang-and-Song era. In the Yuan Dynasty, the Mongol Empire controlled most Islamic countries and areas in the Western regions, which caused the Muslim identity to be no longer considered as a 'foreigner' in China and the Islamic nationality initially formed. After the formation of the Islamic nationality, Muslims' social environment worsened during the Ming era. In response, there arose an awareness of Islamic missionary work and Islamic nationality, and Muslims started communicating with and absorbing the Chinese traditional culture, transforming the pattern of transmitting Islam. During the Qing Dynasty and modern times, Islam and Islamic nationality became an important part of China and played a crucial role in politics and economy.

\section{Conclusion}

In this study, we used Lorenz curve, Gini coefficient, Kernel density analysis, and Pearson correlation coefficient to analyse Islamic cultural heritage in China, specifically the characteristics of its temporal-spatial distribution and factors influencing this distribution, using The Lists of Islamic CRPU in China. The study results indicated that the temporal-spatial distribution of Islamic cultural heritage in China is imbalanced, with most of the relics belonging to the Ming-and-Qing era in temporal distribution, corresponding to the spread and development of Islam in China. The temporal-spatial distribution of Islamic cultural heritage has been influenced by the propagation condition of Islam, the policy and attitude of governors, and the awareness of Islam missionary work and Islamic nationality.

The cultural heritage relics are historical tracks of social development, and the temporal-spatial distribution of Islamic cultural heritage reflects the spread and development of Islam in China. This paper, which discussed the temporal-spatial distribution of Islamic cultural heritage and factors influencing such distribution, illustrates the practical significance of understanding the historical development of Islam in China, making appropriate ethnic and religious policies, and administering religious cultural heritage. The CRPU is historical, as its existence is related to wars, natural disasters, and the system of preserving artefacts that degrade with time. The development of a religion is also influenced by its value, the spiritual needs of certain regions, and conflicts with other religions. All these factors should be further discussed to deepen the understanding of the temporal-spatial distribution of the cultural heritage.

\section{Acknowledgement}

This research was financially supported by the national natural science foundation of China (4117119), Fujian planning project of social science (2014B160) and Fujian provincial science and technology department of public welfare project (2017R1034-3). 


\section{References}

[1] Fitri I, Ahmad Y, Ahmad F. Conservation of Tangible Cultural Heritage in Indonesia: A Review Current National Criteria for Assessing Heritage Value[J]. Procedia - Social and Behavioral Sciences, 2015, 184:71-78.

[2] Madirov E, Absalyamova S. The Influence of Information Technologies on the Availability of Cultural Heritage[J]. Procedia - Social and Behavioral Sciences, 2015, 188:255-258.

[3] Valentina V, Marius-Răzvan S, Ioana-Alexandra L, et al. Innovative Valuing of the Cultural Heritage Assets. Economic Implication on Local Employability, Small Entrepreneurship Development and Social Inclusion[J]. Procedia - Social and Behavioral Sciences, 2015, 188:16-26.

[4] Álvarez J P F, Pieiga G L, Suárez-Lázare C J. New Concepts in Reassessing Mining Heritage: A study and Its Implications from the Ancient Iron Mine of Llumeres (North Spain)[J]. Journal of Cultural Heritage, 2010, 11(2):172-179.

[5] Davis T. From Babylon to Baghdad: Cultural Heritage and Constitutional Law in the Republic of Iraq[J]. International Journal of Cultural Property, 2015, 21(4):445-463.

[6] Bashi E. Cultural Heritage of Albania - A Fabulous Economic Source for the Sustainable Economic Development of Tourism[J]. Procedia - Social and Behavioral Sciences, 2015, 188:89-94.

[7] Pretes M. Touring Mines and Mining Tourists[J]. Annals of Tourism Research, 2002, 29(2):439-456.

[8] Bakar A A, Osman M M, Bachok S, et al. Analysis on Community Involvement Level in Intangible Cultural Heritage: Malacca Cultural Community[J]. Procedia - Social and Behavioral Sciences, 2014, 153:286-297.

[9] Ballesteros E R, Ramírez M H. Identity and Community-Reflections on the Development of Mining Heritage Tourism in Southern Spain[J]. Tourism Management, 2007, 28(3):677-687.

[10] Wu Pingcai, Chu Lei. Theoretical Foundation of Archival Protection of Intangible Cultural Heritage[J]. Archives Science Bulletin, 2012(5):75-77 (in Chinese).

[11]Wang Yunxia. On the Rights to Cultural Heritage[J]. Journal of Renmin University of China, 2011, 2:20-27 (in Chinese).

[12]Wu Qing, Li Xigui, Zhang Ming. The Spatial Distribution and Relevant Factors of China's Different Types Intangible Cultural Heritages[J]. Economic Geography, 2015, 35(6):175-183 (in Chinese).

[13] Nunta J, Sahachaisaeree N. Determinant of Cultural Heritage on the Spatial Setting of Cultural Landscape: A Case Study on the Northern Region of Thailand[J]. Procedia - Social and Behavioral Sciences, 2010, 5:1241-1245.

[14]Zhang Guanglin, Ma Dan. Attache Great Importance to Protect Islam Cultural Heritage in China[J]. Religion in China. 2015(3):16-17 (in Chinese).

[15] Yang Wenqi. The Think about Sustainable Development Strategy of Intangible Cultural Heritage in Ten Muslim Minority[J]. Social Sciences in Ningxia, 2016(5):227-232 (in Chinese).

[16] Yang Wenqi. Value and Types of Islamic Historical Sites under National Protection[J]. China Muslim, 2016(1):22-25 (in Chinese).

[17] Tian Zhengjiang. The Characteristic of Uighur Intangible Cultural Heritage in Turpan[J]. Journal of Social Science of Jiamusi University. 2012, 30(6):149-152 (in Chinese). 
[18]Zhong Jinwen. Cultural Heritage and the Practice of National Identification-Take the Tuomao People for an Example[J]. Journal of Qinghai nationalities University, 2015(3):125-129 (in Chinese).

[19]Dai Xiangyi, Jue Weimin. Temporal-spatial Distribution of Mining Heritages in China: The Perspective of Officially Protected Site/ Entity[J]. Geographical Research, 2011, 30(4):747-757 (in Chinese).

[20]Li Wei, Hu Jing, Lu Rurui. The Temporal and Spatial Distribution Characteristics of Tourist Flows in Special-Term Based on Different Tourism Purposes - A Case Study of Wuhan City[J]. Economic Geography,2013, 33(1):180-186 (in Chinese).

[21]Zhong Yexi, Bao Shuming. Space-Time Analysis of Religious Landscape in China[J]. Tropical Geography, 2014, 34(5):591-598 (in Chinese).

[22] Meng Hang. The Initial Analysis of the Distribution of Muslims in China[J]. North-west Ethno-national Studies, 2004(4):76-96 (in Chinese).

[23]Huang Weimin. The Development and Characteristic of Islam Spread in China[J]. The Journal of Shaanxi Youth Vocational college,2002, 15(3):36-41 (in Chinese).

[24] Ma Zongbao. Studies about Hui Nationality in China[C]. Beijing: Nationalities Publishing House, 2005:168-179 (in Chinese).

[25]Jin Yijiu. The Localization and Nationalization of Islam in China[J]. Studies in World Religions, 1995(1):1-8 (in Chinese).

[26]Zhou Shangyi, Kong Xiang, Zhu Hong. Cultural Geography[M]. Beijing: Higher Education Press, 2004 (in Chinese). 